\title{
Polymorphisms in Matrix Metalloproteinase-1, -9 and -12 Genes and the Risk of Chronic Obstructive Pulmonary Disease in a Korean Population
}

\author{
Shin-Yup Lee ${ }^{a}$ Min-Jung Kim ${ }^{b}$ Hyo-Gyung Kang ${ }^{b}$ Seung-Soo Yoo ${ }^{a}$ \\ Yi-Young Choi ${ }^{b}$ Won-Kee Lee ${ }^{c}$ Seung-Ick Cha ${ }^{a}$ Chang-Ho Kim ${ }^{a}$ \\ Tae-Hoon Jung ${ }^{a}$ Jae-Yong Park ${ }^{a, b}$ \\ Departments of a Internal Medicine, ${ }^{b}$ Biochemistry and 'Preventive Medicine, School of Medicine, \\ Kyungpook National University, Daegu, Republic of Korea
}

\section{Key Words}

Chronic obstructive pulmonary disease $\cdot$ Matrix

metalloproteinases $\cdot$ Polymorphisms

\begin{abstract}
Background: Although a few studies have been conducted to evaluate the association of polymorphisms in matrix metalloproteinase (MMP) genes with chronic obstructive pulmonary disease (COPD), the results have been inconsistent. Objectives: To investigate the association of 3 polymorphisms of MMP genes (MMP-1 -1607G $\rightarrow \mathrm{GG}$, MMP-9 $-1562 C \rightarrow$ T and MMP-12 N357S), which have been reported to be associated with COPD-related phenotypes, with the risk of COPD in a Korean population. Methods: The genotypes of the 3 polymorphisms were determined in 301 patients with COPD and 333 healthy controls. Results: Of the 3 polymorphisms studied, only the distribution of the MMP-9-1562C $\rightarrow$ T genotypes was significantly different between the cases and controls ( $p=0.01$ ), with the frequency of the variant T allele being significantly lower in the cases than in the controls (10.4 vs. $15.7 \% ; p=0.006$ ). Individuals with at least 1 variant $T$ allele were at a significantly decreased risk of COPD when compared with those with homozygous wild-type alleles (adjusted odds ratio $=0.69 ; 95 \% \mathrm{Cl}=0.45-0.98 ; \mathrm{p}=0.04$ ).
\end{abstract}

Conclusions: These findings suggest that the MMP-9 $-1562 \mathrm{C} \rightarrow$ T polymorphism could be used as a marker for determining the genetic susceptibility to COPD in a Korean population.

Copyright $\odot 2010$ S. Karger AG, Base

\section{Introduction}

Chronic obstructive pulmonary disease (COPD) is characterized by progressive irreversible airflow limitation, which is caused by a mixture of small airway disease (obstructive bronchiolitis) and parenchymal destruction (emphysema) [1]. Although cigarette smoking is a major environmental risk factor for COPD, only a fraction of chronic smokers develop symptomatic COPD [2], which suggests that genetic factors play an important role in its development $[3,4]$.

One of the most prevailing hypotheses for the pathogenesis of COPD is an inflammatory theory, which suggests that cigarette smoke and other inhaled irritants

S.Y.L. and M.J.K. have equally contributed to this paper.

\section{KARGER}

Fax +4161306 1234

E-Mail karger@karger.ch

www.karger.com (c) 2010 S. Karger AG, Basel

$0025-7931 / 10 / 0802-0133 \$ 26.00 / 0$

Accessible online at:

www.karger.com/res
Jae-Yong Park, MD

Department of Internal Medicine, Kyungpook National University Hospital Samduk 2a 50

Daegu 700-412 (Republic of Korea)

Tel. +82 53420 5536, Fax +82534262046, E-Mail jaeyong@ knu.ac.kr 
stimulate inflammatory cells such as neutrophils and macrophages to release reactive oxygen species and a variety of proteolytic enzymes. These inflammatory events then lead to a proteinase-antiproteinase imbalance, which results in a degradation of the extracellular matrix of the lung $[1,5]$. Based on this theory, the genes involved in the protease-antiprotease imbalance have attracted attention as candidates for the genetic predisposition to COPD $[3,4]$.

Matrix metalloproteinases (MMP) are a family of zinc-dependent endopeptidases that degrade all the main protein components of the extracellular matrix and basement membrane [6-8]. At least 22 human MMP have been identified to date. The MMP are divided into collagenases, gelatinases, stromelysins and matrilysins based on their substrate specificity. In addition, they are also divided into 8 subgroups according to their structure, 5 of which are secreted and 3 of which are membrane-type MMP [6-8].

It has been reported that transgenic mice that overexpress human MMP-1 (collagenase-1) in their lungs developed morphological changes similar to those observed in human pulmonary emphysema [9]. In addition, a previous study found that MMP-12 (macrophage metalloelastase) knockout mice did not develop emphysema following long-term exposure to cigarette smoke when compared to wild-type mice [10]. Furthermore, Zheng et al. [11] demonstrated that several MMP contribute to the development of emphysema in murine lung. Moreover, several studies have shown that the expression of $M M P-1$ and $M M P-9$ is upregulated in alveolar macrophages or lung tissues from patients with COPD [12-14]. Taken together, these studies in animals and humans indicate that MMP such as MMP-1, -9 and -12 play important roles in cigarette-smoke-induced airway inflammation and the development of COPD.

Due to the important role that MMP play in the pathogenesis of COPD, several studies have investigated the association of polymorphisms in the MMP-1, -9 and -12 genes with COPD-related phenotypes; however, the results of these studies have been inconsistent [15-20]. Therefore, we investigated the association of polymorphisms in the MMP-1, -9 and -12 genes with the risk of COPD in a Korean population. Specifically, in this study, we evaluated the $M M P-1-1607 \mathrm{G} \rightarrow \mathrm{GG}$ ( $\mathrm{rs} 1799750)$, $M M P-9-1562 \mathrm{C} \rightarrow \mathrm{T}(\mathrm{rs} 3918242)$ and $M M P-12 \mathrm{~N} 357 \mathrm{~S}$ $($ rs652438A $\rightarrow \mathrm{G}$ ) polymorphisms, which had been found to be associated with COPD-related phenotypes in the previous studies [15-20].

\section{Methods}

\section{Study Population}

This study included male smokers (current or former) with or without COPD from a Korean population that has been described elsewhere [21]. Briefly, the case group consisted of 301 patients who were diagnosed with COPD at the Kyungpook National University Hospital according to the criteria established by the NHLBI (National Heart, Lung, and Blood Institute)/WHO Global Initiative for COPD (GOLD) [1]. The inclusion criteria for COPD were as follows: (1) chronic respiratory symptoms and signs such as cough and dyspnea, and (2) postbronchodilator $\mathrm{FEV}_{1}<80 \%$ of the predicted value, $\mathrm{FEV}_{1} / \mathrm{FVC}<70 \%$ and $\mathrm{FEV}_{1}$ reversibility after the inhalation of $200 \mu \mathrm{g}$ salbutamol $<12 \%$ of the prebronchodilator $\mathrm{FEV}_{1}$. The severity of COPD was classified by the guidelines of the GOLD in terms of the percent predicted $\mathrm{FEV}_{1}$ : mild $(>80 \%)$, moderate $(50-80 \%)$, severe $(30-50 \%)$ or very severe $(<30 \%)$. Control subjects $(n=333)$ were selected from a pool of healthy men who visited the general health checkup center. The enrollment criteria for the controls were as follows: male, smoker, age $>45$ years, no known disease, no history of any disease and no airflow limitation. All of the cases and the controls were ethnic Koreans who resided in Daegu City or in the surrounding regions. A trained interviewer completed detailed questionnaires for each patient and each control subject. This study was approved by the institutional review board of the Kyungpook National University Hospital, and written informed consent was obtained from each participant.

\section{Genotyping}

The genotypes of the 3 polymorphisms were determined by PCR and melting-curve analysis using fluorescence-labeled hybridization probes (LightCycler; Roche Diagnostics, Mannheim, Germany) [22]. Samples that could not be scored by the LightCycler were regenotyped by direct sequencing using an ABI Prism 3700 genetic analyzer (Applied Biosystems). To confirm the genotyping results, selected PCR-amplified DNA samples were examined by DNA sequencing, and the results were $100 \%$ concordant. All genotyping analyses were blinded with respect to the case/ control status in order to ensure quality control. In addition, approximately $10 \%$ of the samples were randomly selected to be genotyped again by a different investigator, and the results were $100 \%$ concordant.

\section{Statistical Analysis}

The cases and controls were compared using the Student t test for continuous variables and a $\chi^{2}$ test for categorical variables. The Hardy-Weinberg equilibrium for each genotyped polymorphism was tested using the goodness-of-fit test, as implemented via SAS/ Genetics. Unconditional logistic regression analyses were used to calculate the odds ratios (OR) and 95\% CI, with adjustment for possible confounders (age and pack years of smoking as continuous variables). In addition to the overall association analysis, we performed a stratified analysis according to age, smoking status and severity of COPD to further explore the association between genotypes and the risk of COPD in each stratum. To assess the potential interaction between genotype and smoking (smoking status or pack years of smoking), we first included the interaction term in the logistic model. The interaction between genotype and smoking was not statistically significant; therefore, it was re- 
moved from the model. To correct for multiple testing, we applied a false discovery rate. A homogeneity test was conducted to compare the difference between genotype-related OR of different groups. All of the analyses were performed using the Statistical Analysis Software for Windows, version 9.1.3 (SAS Institute, Gary, N.C., USA).

Table 1. Characteristics of the study population

\begin{tabular}{lccc}
\hline & $\begin{array}{l}\text { COPD } \\
(\mathrm{n}=301)\end{array}$ & $\begin{array}{l}\text { Control } \\
(\mathrm{n}=333)\end{array}$ & $\mathrm{p}$ \\
\hline $\begin{array}{l}\text { Age, years } \\
\text { Smoking status, } \mathrm{n}\end{array}$ & $65.7 \pm 8.0$ & $60.4 \pm 8.2$ & $\begin{array}{c}<0.001^{\mathrm{a}} \\
0.19^{\mathrm{b}}\end{array}$ \\
$\quad$ Current & $170(56.5)$ & $205(61.6)$ & \\
$\quad$ Former & $131(43.5)$ & $128(38.4)$ & \\
Pack-years & $43.2 \pm 20.2$ & $30.8 \pm 16.9$ & $<0.001^{\mathrm{a}}$ \\
FEV $_{1}, \%$ predicted & $63.0 \pm 26.2$ & $103.9 \pm 16.6$ & $<0.001^{\mathrm{a}}$ \\
FEV $_{1} /$ FVC, \% & $49.4 \pm 13.1$ & $80.3 \pm 7.4$ & $<0.001^{\mathrm{a}}$ \\
\hline
\end{tabular}

Values in parentheses are column percentages.

${ }^{a}$ t test. ${ }^{b} \chi^{2}$ test.

\section{Results}

The baseline characteristics of the cases and controls enrolled in this study are shown in table 1 . There were no significant differences in smoking status between cases and controls. However, the age and the number of pack years were significantly higher in the cases than in the controls (age: $65.7 \pm 8.0$ vs. $60.4 \pm 8.2$ years, $\mathrm{p}<0.001$; pack years: $43.2 \pm 20.2$ vs. $30.8 \pm 16.9, \mathrm{p}<0.001)$. These differences were controlled in the later multivariate analyses. The $\mathrm{FEV}_{1}$ and $\mathrm{FEV}_{1} / \mathrm{FVC}$ ratio were significantly lower in the COPD group than in the control group.

The genotype and polymorphic allele frequencies of the 3 polymorphisms in the cases and controls are shown in table 2 . The genotyping success rate was $98.3 \%$ (99.0\% in the cases and $97.8 \%$ in the controls) for all the $3 M M P$ polymorphisms. The genotype distributions of the 3 polymorphisms in the controls and cases were consistent with the Hardy-Weinberg equilibrium. The distribution of the MMP-9 -1562C $\rightarrow \mathrm{T}$ genotypes was significantly

Table 2. Genotype frequencies of $M M P$ gene polymorphisms in COPD cases and controls

\begin{tabular}{|c|c|c|c|c|c|}
\hline Polymorphism/Genotype ${ }^{1}$ & $\begin{array}{l}\text { Cases } \\
(\mathrm{n}=301)\end{array}$ & $\begin{array}{l}\text { Controls } \\
(\mathrm{n}=333)\end{array}$ & $\mathrm{p}^{1}$ & Adjusted $\mathrm{OR}^{2}$ & $\mathrm{p}^{2}$ \\
\hline \multicolumn{6}{|l|}{$M M P-1-1607 \mathrm{G} \rightarrow \mathrm{GG}^{3}$} \\
\hline $\mathrm{G} / \mathrm{G}$ & $29(9.7)$ & $42(12.7)$ & 0.38 & $0.93(0.53-1.64)$ & 0.80 \\
\hline G/GG & $128(42.7)$ & $128(38.7)$ & & $1.34(0.93-1.93)$ & 0.12 \\
\hline GG/GG & $143(47.7)$ & $161(48.6)$ & & 1.00 & \\
\hline $\mathrm{C} / \mathrm{C}$ & $234(79.6)$ & $226(71.5)$ & 0.01 & 1.00 & \\
\hline $\mathrm{C} / \mathrm{T}$ & $59(20.1)$ & $81(25.6)$ & & $0.79(0.50-1.06)$ & 0.09 \\
\hline $\mathrm{T} / \mathrm{T}$ & $1(0.3)$ & $9(2.9)$ & & $0.08(0.01-0.62)$ & $0.02^{5}$ \\
\hline PAF & 0.104 & 0.157 & 0.006 & & \\
\hline $\mathrm{C} / \mathrm{C}$ & $234(79.6)$ & $226(71.5)$ & 0.02 & 1.00 & \\
\hline $\mathrm{C} / \mathrm{T}+\mathrm{T} / \mathrm{T}$ & $60(20.4)$ & $90(28.5)$ & & $0.69(0.45-0.98)$ & $0.04^{5}$ \\
\hline PAF & 0.062 & 0.071 & 0.86 & & \\
\hline $\begin{array}{l}\text { Values in parentheses ar } \\
{ }^{1} \text { Two-sided } \chi^{2} \text { test for e } \\
2 \text { OR }(95 \% \mathrm{CI}) \text { and their } \\
\text { pack-years of smoking. } \\
{ }^{3} \text { Individuals with missi } \\
\text { type data were: } 1 \text { and } 2 \text { for } \\
{ }^{4} \text { Polymorphic allele fre } \\
{ }^{5} \text { False-discovery-rate-a }\end{array}$ & $\begin{array}{l}\text { tages or } 950 \\
\text { otype distri } \\
\text { onding } p \text { val } \\
\text { type data we } \\
-160 \mathrm{G} \rightarrow \mathrm{GQ} \\
\text { value }>0.0\end{array}$ & $\begin{array}{l}\text { ted OR colu } \\
\text { tween the ca } \\
\text { alculated by } \\
\text { uded in the } \\
\text { for } M M P-9\end{array}$ & $\begin{array}{l}\text { ntrols. } \\
\text { onal log } \\
\text { he num } \\
\text { and } 2\end{array}$ & $\begin{array}{l}\text { ession analysis, ad } \\
\text { ses and controls w } \\
M M P-12 \text { N357S, }\end{array}$ & $\begin{array}{l}\text { age and } \\
\text { g geno- } \\
\text { y. }\end{array}$ \\
\hline
\end{tabular}


different between the cases and controls (CC, CT and TT genotypes: $79.6,20.1$ and $0.3 \%$ vs. $71.5,25.6$ and $2.9 \%$, respectively; $\mathrm{p}=0.01$ ), with the frequency of the variant $\mathrm{T}$ allele being significantly lower in the cases than in the controls (10.4 vs. $15.7 \%$; $p=0.006)$. Individuals with at least 1 variant $\mathrm{T}$ allele were at a significantly decreased risk of COPD when compared with those with homozygous wild-type alleles (adjusted $\mathrm{OR}=0.69 ; 95 \% \mathrm{CI}=$ $0.45-0.98 ; \mathrm{p}=0.04)$. There was no significant difference in the genotype distributions of the other $2 M M P$ polymorphisms between the cases and controls.

\section{Discussion}

This study has been performed as part of a series of candidate gene association studies that primarily focused on genes selected on the basis of prior knowledge of the COPD biology, including genes involved in protease-antiprotease balance, oxidative stress, the xenobiotic metabolism of toxins, and inflammatory or immune response $[3,23]$. In the present study, we investigated the association between 3 polymorphisms in $M M P$ genes (MMP-1, -9 and -12) that had previously been reported to be associated with COPD-related phenotypes and the risk of COPD in a Korean population. Of the 3 polymorphisms evaluated, the $M M P-9-1562 \mathrm{C} \rightarrow$ T polymorphism was found to be significantly associated with the risk of COPD; however, the MMP-1 -1607G $\rightarrow \mathrm{GG}$ and $M M P-12$ N357S polymorphisms were not associated with the risk of COPD.

Among the polymorphisms in the $M M P-1,-9$ and -12 genes, we focused on the MMP-1 -1607G $\rightarrow \mathrm{GG}, M M P-9$ $-1562 \mathrm{C} \rightarrow \mathrm{T}$ and $M M P-12 \mathrm{~N} 357 \mathrm{~S}$ polymorphisms because it has been suggested that they influence gene expression or function, and because it has been reported that they are associated with COPD [15-20]. The insertion of a G allele at position -1607 (-1607GG allele) in the promoter of the MMP-1 gene has been shown to create a binding site for the ETS-1 transcription factor, which results in enhanced gene expression [24]. In addition, it has been suggested that the MMP-9 $-1562 \mathrm{C} \rightarrow \mathrm{T}$ polymorphism decreases the binding affinity for a transcriptional repressor, thereby increasing $M M P-9$ expression $[25,26]$. Although the functional effect of the MMP-12 N357S polymorphism is not known, it has been suggested that an amino acid change from acidic Asn to hydroxylic Ser alters the catalytic activity of the protein [16].

Although a few studies have investigated the association between $M M P$ polymorphisms and the risk of COPD, the results of these studies have been inconsistent. Minematsu et al. [15] and Ito et al. [19] investigated the association of the MMP-9 $-1562 \mathrm{C} \rightarrow \mathrm{T}$ polymorphism with COPD-related phenotypes in Japanese populations. They found that, although the frequency of the $-1562 \mathrm{~T}$ allele was not significantly different between COPD patients and healthy controls, COPD patients with the $-1562 \mathrm{~T}$ allele showed more severe emphysema (lower DLCO/VA and/or higher attenuation area score as indicated by chest computed tomography) when compared to patients who did not have the $-1562 \mathrm{~T}$ allele. Based on these results, these authors suggested that the $-1562 \mathrm{C} \rightarrow \mathrm{T}$ polymorphism acts as a genetic factor for the development of pulmonary emphysema. However, in a study investigating the association of 5 polymorphisms in the MMP genes $[M M P-1 \quad-1607 \mathrm{G} \rightarrow \mathrm{GG}$ and (CA)-repeat, MMP-9 $-1562 \mathrm{C} \rightarrow \mathrm{T}$, and $M M P-12-82 \mathrm{~A} \rightarrow \mathrm{G}$ and N357S] with the rate of decline of lung function in mild-to-moderate COPD patients from the multicenter Lung Health Study population [16], the MMP-9 $-1562 \mathrm{C} \rightarrow \mathrm{T}$ polymorphism was not found to be associated with the rate of decline of lung function, whereas the MMP-1 -1607GG allele was associated with a rapid decline of lung function. Moreover, Hersh et al. [18] reported that the MMP-1 $-1607 \mathrm{G} \rightarrow \mathrm{GG}$ and $(\mathrm{CA})$-repeat polymorphisms were not associated with the risk of COPD in a family study of severe early-onset COPD pedigrees and a case-control study of American Caucasians. In the present study, of the 3 polymorphisms studied $(M M P-1-1607 \mathrm{G} \rightarrow \mathrm{GG}$, $M M P-9-1562 \mathrm{C} \rightarrow \mathrm{T}$ and $M M P-12 \mathrm{~N} 357 \mathrm{~S})$, only the $M M P$ $9-1562 \mathrm{C} \rightarrow$ T polymorphism was associated with the risk of COPD. Although the reasons for the different results across studies are unclear, these inconsistencies may be due to true variability in genetic determinants among different ethnic populations, phenotypic heterogeneity, population stratification and false-negative or -positive studies $[18,27,28]$.

In the previous studies $[25,26]$, the $\mathrm{T}$ allele of the $M M P-9-1562 \mathrm{C} \rightarrow \mathrm{T}$ polymorphism has been found to increase $M M P-9$ expression, therefore it could be expected to increase smoking-related lung injury and the susceptibility to COPD. However, in the present study, the $-1562 \mathrm{~T}$ allele was associated with a decreased risk of COPD, which is similar to the results of several previous studies. For example, Woo et al. [29] also reported that the MMP-9 -1562T allele was protective against the development of colorectal cancer. Although it is hard to decipher the mechanism(s) responsible for the oppositely directed (flip-flop) association of the MMP-9-1562C $\rightarrow \mathrm{T}$ polymorphism with COPD across studies, the different 
genetic backgrounds in the study populations may have been responsible for this discrepancy. The frequencies of MMP-9 single-nucleotide polymorphisms (SNPs) and the status of linkage disequilibrium between the SNPs may differ among ethnic groups; therefore, the genetic effects of the MMP-9 $-1562 \mathrm{C} \rightarrow \mathrm{T}$ polymorphism on the susceptibility to COPD may differ by ethnicity. In a complex polygenic disease such as COPD, it is likely that multiple genes are involved in its pathogenesis, which would result in the genetic susceptibility being dependent on the several polymorphisms acting in concert. As a result, a protective genotype in one population may increase the risk of COPD in another population due to other linked polymorphisms that exhibit stronger effects on the susceptibility to COPD. This discrepancy may be related to differences in the distribution of COPD phenotypes across studies. COPD is a heterogeneous disorder that includes obstructive bronchiolitis and emphysema. Although these COPD phenotypes share some similar pathophysiology and likely share some similar genetic determinants, there may also be divergent underlying pathways involved in their development. Accordingly, it is possible that the effects of the MMP-9 SNP on the risk of COPD will differ according to the phenotype of COPD $[30,31]$.

There are several potential limitations to the present study. One such limitation is the small sample size. The sample size used in this study only enabled the identification of variants that exert a relatively large effect on the risk of COPD, while it did not have sufficient statistical power for the detection of variants that had a small effect on disease susceptibility; therefore, there might be type II errors in the analysis. In addition, the corrected $p$ values for multiple comparisons did not reach statistical sig- nificance, which indicates that there may be type I errors. In addition, the present study was not powered to perform subgroup analyses for age, smoking status and disease severity. Accordingly, additional studies with larger sample sizes are required to confirm our findings.

Another limitation is that our study did not include the related functional assays, which limited our evaluation of the biological mechanisms involved in the observed associations between the SNPs and COPD risk. In addition, one must consider potential biases that might influence the results of hospital-based case-control studies, such as selection and information biases, which were described in our study.

In conclusion, we found that the MMP-9 $-1562 \mathrm{C} \rightarrow \mathrm{T}$ polymorphism contributes to the development of COPD. In addition, we found that the effect of this polymorphism is more pronounced in older individuals and heavier smokers. Taken together, these findings suggest that the MMP-9-1562C $\rightarrow$ T polymorphism could be used as a marker for determining the genetic susceptibility to COPD. However, due to the relatively small sample size, it is possible that our findings occurred by chance. Therefore, additional studies with larger sample sizes are required to confirm our findings. Future studies of other $M M P-9$ variants and their biologic function are also needed to understand the role of $M M P-9$ polymorphisms in the risk of COPD.

\section{Acknowledgment}

This study was supported by a grant from the Korean Healthcare Technology R\&D Project, Ministry of Health, Welfare and Family Affairs, Republic of Korea (grant No. A090460).

\section{References}

1 Rabe KF, Hurd S, Anzueto A, Barnes PJ, Buist SA, Calverly P, Fukuchi Y, Jenkins C, Rodriguez-Roisin R, van Weel C, Zielinski J: Global strategy for the diagnosis, management, and prevention of chronic obstructive pulmonary disease: GOLD executive summary. Am J Respir Crit Care Med 2007;176: 532-555.

2 Lokke A, Lange P, Scharling H, Fabricius P, Vestbo J: Developing COPD: a 25-year follow-up study of the general population. Tho$\operatorname{rax} 2006 ; 61: 935-939$.
-3 Sandford AJ, Silverman EK: Chronic obstructive pulmonary disease. 1. Susceptibility factors for COPD the genotype-environment interaction. Thorax 2002;57:736-741.

4 Caramori G, Adcock I: Gene-environment interactions in the development of chronic obstructive pulmonary disease. Curr Opin Allergy Clin Immunol 2006;6:323-328.

5 Groneberg DA, Chung KF: Models of chronic obstructive pulmonary disease. Respir Res 2004;5:18.

6 Sternlicht MD, Werb Z: How matrix metalloproteinases regulate cell behavior. Annu Rev Cell Dev Biol 2001;17:463-516.
7 Egeblad M, Werb Z: New functions for the matrix metalloproteinases in cancer progression. Nat Rev Cancer 2002;2:161-174.

8 Overall CM, López-Otín C: Strategies for MMP inhibition in cancer: innovations for the post-trial era. Nat Rev Cancer 2002;2: 657-672.

\9 D’Armiento J, Dalal SS, Okada Y, Berg RA, Chada K: Collagenase expression in the lungs of transgenic mice causes pulmonary emphysema. Cell 1992;71:955-961.

10 Hautamaki RD, Kobayashi DK, Senior RM, Shapiro SD: Requirement for macrophage elastase for cigarette smoke-induced emphysema in mice. Science 1997;277:2002-2004. 
-11 Zheng T, Zhu Z, Wang Z, Homer RJ, Ma B, Riese RJ, Chapman HA, Shapiro SD, Elias JA: Inducible targeting of IL-13 to the adult lung causes matrix metalloproteinase- and cathepsin-dependent emphysema. J Clin Invest 2000;106:1081-1093.

-12 Finlay GA, O’Driscoll LR, Russell KJ, D’Arcy EM, Masterson JB, FitzGerald MX, O'Connor CM: Matrix metalloproteinase expression and production by alveolar macrophages in emphysema. Am J Respir Crit Care Med 1997;156:240-247.

13 Segura-Valdez L, Pardo A, Gaxiola M, Uhal BD, Becerril C, Selman M: Upregulation of gelatinase $\mathrm{A}$ and $\mathrm{B}$, collagenase 1 and 2 , and increased parenchymal cell death in COPD. Chest 2000;117:684-694.

-14 Russell REK, Culpitt SV, DeMatos C, Donnelly L, Smith M, Wiggins J, Barnes PJ: Release and activity of matrix metalloproteinase- 9 and tissue inhibitor of metalloproteinase- 1 by alveolar macrophages from patients with chronic obstructive pulmonary disease. Am J Respir Cell Mol Biol 2002;26: 602-609.

- 15 Minematsu N, Nakamura H, Tateno H, Nakajima T, Yamaguchi K: Genetic polymorphism in matrix metalloproteinase-9 and pulmonary emphysema. Biochem Biophys Res Commun 2001;289:116-119.

$\checkmark 16$ Joos L, He JQ, Shepherdson MB, Connett JE, Anthonisen NR, Pare PD, Sandford AJ: The role of matrix metalloproteinase polymorphisms in the rate of decline in lung function. Hum Mol Genet 2002;11:569-576.

17 Zhou M, Huang SG, Wan HY, Li B, Deng WW, Li M: Genetic polymorphism in matrix metalloproteinase- 9 and the susceptibility to chronic obstructive pulmonary disease in Han population of south China. Chin Med J 2004;117:1481-1484.
18 Hersh CP, DeMeo DL, Lange C, Litonjua AA, Reilly JJ, Kwiatkowski D, Laird N, Sylvia JS, Sparrow D, Speizer FE, Weiss ST, Silverman EK: Attempted replication of reported chronic obstructive pulmonary disease candidate gene associations. Am J Respir Crit Care Med 2005;172:71-78.

19 Ito I, Nagai S, Handa T, Muro S, Hirai T, Tsukino M, Mishima M: Matrix metalloproteinase-9 promoter polymorphism associated with upper lung dominant emphysema. Am J Respir Crit Care Med 2005;172:13781382.

20 Saitoh W, Sakamoto T, Hegab A, Nomura A, Ishii Y, Morishima Y, Kai S, Lizuka T, Kiwamoto T, Matsuno Y, Massoud HH, Massoud HM, Hassanein KM, Sekizawa K: MMP14 gene polymorphisms in chronic obstructive pulmonary disease. Int J Mol Med 2006;17: 621-626.

21 Kim KM, Park SH, Kim JS, Lee WK, Cha SI, Kim CH, Kang YM, Jung TH, Kim IS, Park JY: Polymorphisms in the type IV collagen alpha3 gene and the risk of chronic obstructive pulmonary disease. Eur Respir J 2008; 32:1-7.

22 Kang HG, Lee SJ, Chae MH, Lee WK, Cha SI, Kim CH, Kam S, Park RW, Kim IS, Kim DS, Kim YC, Jung TH, Park JY: Identification of polymorphisms in the XIAP gene and analysis of association with lung cancer risk in a Korean population. Cancer Genet Cytogenet 2008; 180:6-13.

23 Sampsonas F, Karkoulias K, Kaparianos A, Spiropoulos K: Genetics of chronic obstructive pulmonary disease, beyond a1-antitrypsin deficiency. Curr Med Chem 2006;13: 2857-2873.

24 Rutter JL, Mitchell TI, Butticè G, Meyers J, Gusella JF, Ozelius LJ, Brinckerhoff CE: A single-nucleotide polymorphism in the matrix metalloproteinase-1 promoter creates an Ets binding site and augments transcription. Cancer Res 1998;58:5321-5325.
5 Zhang B, Ye S, Herrmann SM, Eriksson P, de Maat M, Evans A, Arveiler D, Luc G, Cambien F, Hamstein A, Watkins H, Henney AM: Functional polymorphism in the regulatory region of gelatinase $\mathrm{B}$ gene in relation to severity of coronary atherosclerosis. Circulation 1999;99:1788-1794.

26 Blankenberg S, Rupprecht HJ, Poirier O, Bickel C, Smieja M, Hafner G, Meyer J, Cambien F, Tiret L: Plasma concentrations and genetic variation of matrix metalloproteinase 9 and prognosis of patients with cardiovascular disease. Circulation 2003;107:15791585.

27 Silverman EK, Palmer LJ: Case-control association studies of the genetics of complex respiratory diseases. Am J Respir Cell Mol Biol 2000;22:645-648.

28 Lee JM, Kang YR, Park SH, Cha SI, Kim JS, Kang HK, Lee WK, Kim MJ, Kim CH, Kim NS, Jung TH, Park JY: Polymorphisms in the interleukin-1B and its receptor antagonist genes and the risk of chronic obstructive pulmonary disease in a Korean population: a case-control study. Res Med 2008;102:13111320 .

29 Woo M, Park K, Nam J, Kim JC: Clinical implications of matrix metalloproteinase-1, -3 , $-7,-9,-12$, and plasminogen activator inhibitor-1 gene polymorphisms in colorectal cancer. J Gastroenterol Hepatol 2007;22:10641070.

30 Litonjua A, Weiss ST: Phenotypes for human respiratory genetics; in Silverman EK, Shapiro SD, Lomas DA, Weiss ST (eds): Respiratory Genetics. London, Edward Arnold, 2005, pp 15-26.

31 Hersh CP, DeMeo DL, Silverman EK: Chronic obstructive pulmonary disease; in Silverman EK, Shapiro SD, Lomas DA, Weiss ST (eds): Respiratory Genetics. London, Edward Arnold, 2005, pp 253-296. 
